\title{
Plastic General Instability of Ring-Stiffened Conical Shells under
} External Pressure

\author{
C. T. F. Ross ${ }^{1 \mathrm{a}}$, G. Andriosopoulos ${ }^{1 \mathrm{~b}}$ and A. P. F. Little ${ }^{1 \mathrm{c}}$ \\ ${ }^{1}$ The University of Portsmouth, Department of Mechanical Engineering, Anglesea Road, \\ Portsmouth PO1 3DJ, UK
}

acarl.ross@ntlworld.com, ${ }^{\mathrm{b}} \mathrm{g}$ andriosopoulos@hotmail.co.uk, aarew.little@port.ac.uk

Keywords: Plastic general instability, ring-stiffened cones, external pressure, finite elements.

\begin{abstract}
The paper describes experimental tests carried out on three ring-stiffened circular conical shells that suffered plastic general instability under uniform external pressure. The cones were carefully machined from EN1A mild steel to a very high degree of precision. The end diameters of the cones, together with their thicknesses were the same, but the size of their ring stiffeners was different for each of the three vessels. In the general instability mode of collapse, the entire ring-shell combination buckles bodily in its flank.

The paper also provides three design charts using the results obtained from these three vessels, together with the results obtained for twelve other vessels from other tests. All 15 vessels failed by general instability. One of these design charts was based on conical shell theory and two of the design charts were based on the general instability of ring-stiffened circular cylindrical shells, using Kendrick's theory, which were made equivalent to ring-stiffened circular conical shells suffering from general instability under uniform external pressure. The design charts allowed the possibility of obtaining plastic knockdown factors, so that the theoretical elastic buckling pressures, for perfect vessels, could be divided by the appropriate plastic knockdown factor, to give the predicted buckling pressure. The theoretical work is based on the solutions of Kendrick, together with the finite element program of Ross, namely RCONEBUR and the commercial finite element package ANSYS. This method can also be used for the design of full-scale vessels.
\end{abstract}

\section{Introduction.}

Submarine pressure hulls usually take the form of ring stiffened circular cylinders and cones blocked off by dome ends. If a long thin-walled circular cylinder or cone is not ring-stiffened, its buckling resistance under uniform external pressure is abysmally poor, [1]. Such a vessel may fail by non-symmetric bifurcation buckling, or shell instability. One method of greatly improving the buckling resistance of such vessels is to ring-stiffen them in their flanks. If, however, the ringstiffeners are not strong enough the entire ring-shell combination can collapse due to the application of uniform external pressure. This mode of failure is known as general instability [2-7]; see Figure 1.

Exact theoretical analysis of many of these structures has been defied, so far, particularly for the less slender vessels that buckle by plastic deformation, as the slightest initial out-of-circularity causes the vessels to fail at buckling pressures that are much lower than that predicted by theory. The reason for this is partly because the initial out-of-circularity is random and difficult to model. In practice, this random initial out-of-circularity grows non-linearly with increase in uniform external pressure so that one part of the vessel becomes plastic. When this occurs, the tangent modulus of the vessel in the area that has suffered plastic deformation decreases to quite a small value. This further complicates the deformation, and causes other parts of the structure, also to 
suffer plastic deformation. The situation is then worsened and eventually the vessel suffers sudden and catastrophic failure.

\section{Figure 1. Buckled Forms of Ring-stiffened Cones 13, 14 and 15.}

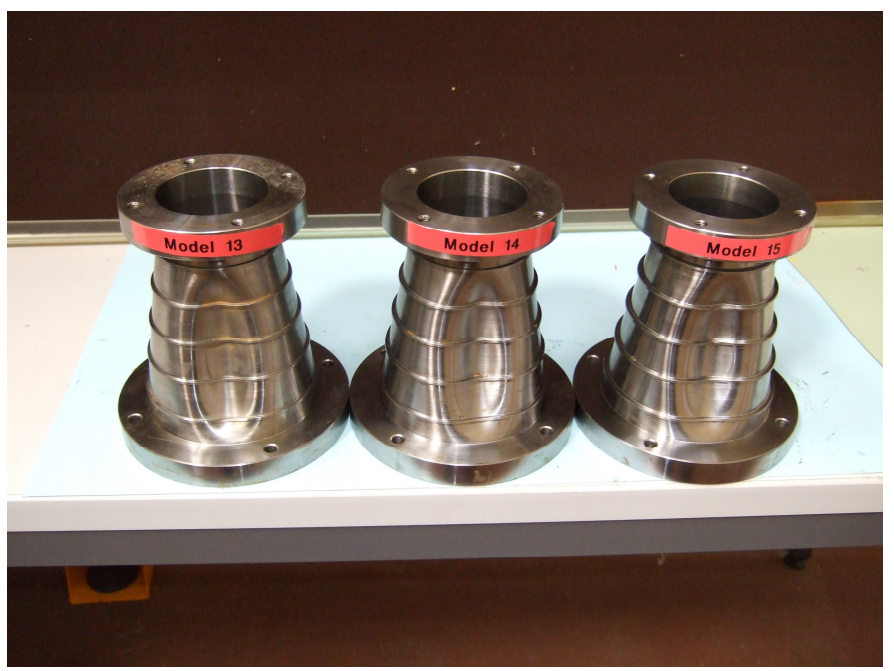

Elastic analysis does, however, usually predict the number of circumferential waves (n) that the vessel buckles into. Because of this, the method proposed here is firstly to calculate the theoretical elastic buckling pressure for a perfect vessel, namely $\mathrm{P}_{\mathrm{cr}}$, together with the thinness ratio, namely $\lambda$, [1,4-7]. Next, by using the appropriate design chart, to obtain the plastic knockdown factor (PKD), the predicted buckling pressure, namely $\mathrm{P}_{\exp }$ is obtained by dividing $\mathrm{P}_{\mathrm{cr}}$ by $\mathrm{PKD}$, as follows:

$\mathrm{P}_{\exp }=\mathrm{P}_{\mathrm{cr}} / \mathrm{PKD}$

The design buckling pressure, namely $\mathrm{P}_{\text {des }}$ is then obtained by dividing $\mathrm{P}_{\exp }$ by a suitable safety factor, namely SF (quite large), as follows:

$\mathrm{P}_{\text {des }}=\mathrm{P}_{\text {exp }} / \mathrm{SF}$

The thinness ratio is dependent on the following parameters of the vessel:

Mean diameter; equivalent wall thickness; overall length; Young's modulus of elasticity \& Yield stress.

\section{Details of the ring-stiffened cones.}

The ring-stiffened conical shells were named Cone 13, Cone 14 and Cone 15. They were machined from EN1A mild steel to the dimensions shown in Figure 2.

Experimental tests on the mild steel ENlA, revealed the following material properties: $\sigma_{\mathrm{yp}}=$ Yield Stress $=250 \mathrm{MPa} ; \mathrm{E}=$ Young's modulus=1.93E5 MPa; $v=$ Poisson's ratio $=0.3$

The dimensions of the vessels were measured on a Mitutoya Coordinate Measuring Machine and the maximum initial out-of-circularity was approximately $0.018 \mathrm{~mm}$.

\section{Experimental Method.}

Four circumferential foil strain gauges were connected to the inside of each cone and as the strain gauges were not in the water, they did not need to be waterproofed. The strain gauges were connected at equal intervals along part of the circumference for each conical vessel, at a position under the second ring stiffener measured from the base of the larger diameter of the cone. A fifth gauge was positioned near one of the four circumferential strain gauges, near the base of the cone, in order to measure longitudinal strain. 


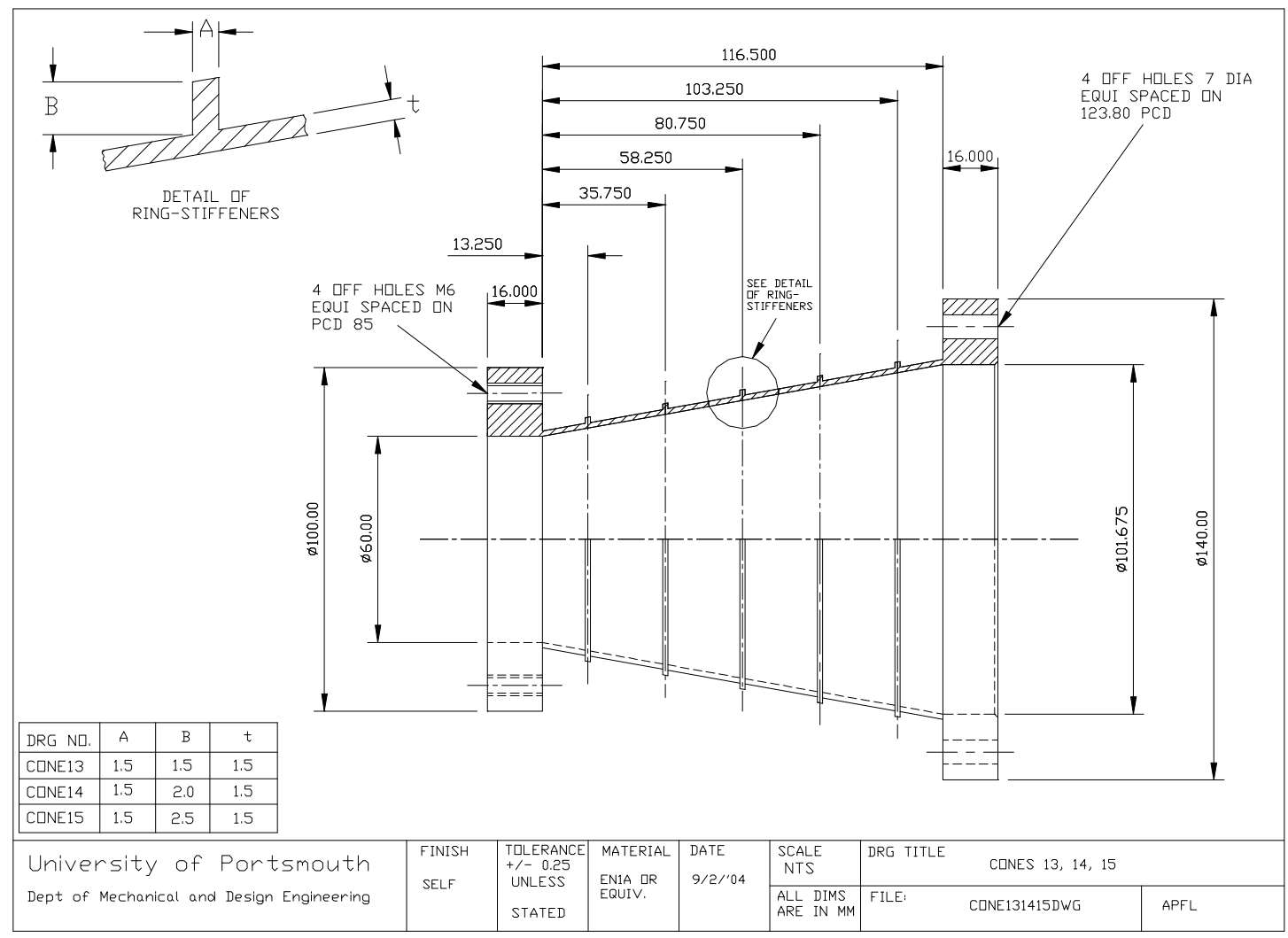

Figure 2. Dimensions of Cones 13, 14 \& 15.

The gauges were then connected to a junction box of strain testers in line with a strain indicator. The vessel was fixed to the top of the tank and the tank was filled with water early enough to allow it to settle to room temperature. The tank was rated to 207 bar. Each conical model was put in the vessel containing water and bolted down. A hydraulic pump, rated to 414 bar, was used to pressurise the vessels.

The vessel was bled from the top of the tank, where any trapped air was removed by pumping in water up to a pressure of about 0.5 bar, with the 'bleeding' bolt removed at the top of the vessel. When the air was pumped out, the 'bleeding' bolt was screwed back into the tank top with some PTFE tape to make it water and pressure proof. Pressures in the test tank were then built up in increments of 6.89 bar $(100 \mathrm{psi})$. At each interval, strains reading on the strain indicator were recorded for the five gauges. When the strain values started to become non-linear around the circumference, the incremental pressures were decreased to 3.44 bar (50 psi). In all cases, the measured strain values from the cones were in the plastic region just before collapse. Cone 13 collapsed in the general instability mode at a pressure of 2040 psi ( 140.7 bar), with a solitary lobe in its flank, as shown in Fig. 1. Cone 14 collapsed in the general instability mode at a pressure of 2110 psi (145.5 bar), with a solitary lobe in its flank. Cone 15 collapsed in the general instability mode at a pressure of 2100 psi (144.8 bar), with a solitary lobe in its flank. The fact that Cone 15 collapsed at a lower pressure than Cone 14, when in fact Cone 15 had deeper rings than Cone 14, everything else being the same, shows that in the Case of Cone 15 we got a rogue result; this indicates that the 'exact' analysis of these vessels is defied. In all cases the strains appeared to be in the plastic zone just before collapse. The strain measurements revealed that the maximum strain for Cones $13,14 \& 15$ were $2495,3456 \& 3616$ micro-strain, respectively. Thus, the cones that had the deeper rings appeared to suffer more plastic deformation than those with the shallower rings; this behaviour was expected. 


\section{Theoretical Analyses.}

Kendrick's theories. The theoretical analyses reported in this section were based on small deflection elastic theory. It will only be briefly described in the present text, as it is fully described elsewhere, $[1,3,4]$. Kendrick assumed a simple trignometrical expression to represent the buckled forms of the ring-stiffened circular cylinders. For both Part 1 and Part 3, these deformation patterns corresponded to simply supported ends. Next, Kendrick substituted these deformation patterns, together with their appropriate derivatives into integrals for the strain energy of the shell and stiffening rings, together with the potential of the system. After integrating these equations explicitly, Kendrick applied the Rayleigh-Ritz theory to the total strain energy and potential and hence, he obtained the value for $\mathrm{P}_{\text {cr. }}$ The value for $\mathrm{P}_{\mathrm{cr}}$ is the minimum value corresponding to the appropriate value of $n$. the number of circumferential waves that the vessel buckles into. Each theoretical buckling pressure corresponds to a value of $n$, the number of circumferential waves that the vessel buckles into and the value of the chosen $\mathrm{P}_{\mathrm{cr}}$ for each vessel is the minimum value.

Finite element analyses. Prior to this simple analysis the authors carried out much more complicated finite element analyses using ANSYS and also with an in-house axisymmetric shell program called RCONEBUR [1]. The element used in ANSYS was the shell 93. This was an 8node quadrilateral structural shell element. This element was suitable to model curved shells. It had six degrees of freedom at each node. These were translations in the $\mathrm{x}, \mathrm{y}$, and $\mathrm{z}$ directions and rotations about the nodal $\mathrm{x}, \mathrm{y}$, and $\mathrm{z}$-axes. The element had additional facilities such as plasticity, stress stiffening, large deflection, and large strain capabilities. The element was allowed to have variable thickness if required; this was assumed to vary smoothly over the area of the element, with the thickness defined at the corner nodes. In this case, the thickness at the mid-side node was taken as the average of the corresponding corner nodes. If the element had a constant thickness, only the thickness at the I-node, needed to be entered.

The stiffeners were modelled with a Beam 44-tapered beam element, with an offset added. The beam element's x-axis was oriented from node I towards node J. For the two-node option, the default $\left(\theta=0^{0}\right)$ orientation of the element's y-axis was automatically calculated to be parallel to the global X-Y plane. The angle $\theta$ (Theta) or the third option can be used for control of the element orientation about the beam element's x-axis. The third node $(\mathrm{k})$, when used, had an overriding influence over the angle $\theta$ when both were used. The node $(\mathrm{k})$ defined a plane (with I and J) containing the beam element's $\mathrm{x}$ and z-axes.

The shell was modelled in a strip of six elements copied around, with a total of 72 strips. The breakdown of the total number of elements used was:

Shell elements $=432$; Beam elements $=720$; Total number of elements $=1152$

The above finite element analysis took several days to calculate $\mathrm{P}_{\mathrm{cr}}$ for the three cones reported here, largely because of the difficulty of modelling each ring-stiffener and ensuring that its nodes mated exactly with the nodes of its adjacent shell elements.

The other finite element solution used was that of Ross [1]; this was much simpler than ANSYS and took only a couple of hours to analyse one cone. This analysis used a computer program called RCONEBUR; the Kendrick solutions took only a few minutes. RCONEBUR was an in-house program written by Ross [1] in Quickbasic.. It used truncated conical, axisymmetric elements with two nodal circles at each end; each node had four degrees of freedom (i.e., 8 per element). Values for $\mathrm{P}_{\mathrm{cr}}$ calculated from this program were very similar to the values calculated from ANSYS.

The assumed displacement function in the meridional direction for the conical shell element was linear for the meridional and circumferential displacements and cubic for the lateral displacement. In the azimuthal direction, the assumed displacement function for all three displacements was sinusoidal, just like Kendrick [2,3]. By assuming a sinusoidal variation in the azimuthal direction, it was possible to use truncated conical shell elements and thus decrease both computational and preparation time. 
It should be noted that by assuming a sinusoidal variation for the three displacements in the azimuthal direction, explicit integration in this direction was possible thereby considerably reducing the number of elements that were required. From the above descriptions, it can be seen that by applying the theories of Kendrick to an equivalent cone, design time was much reduced.

A computer model of a ring-stiffened cone, using ANSYS, together with the buckled form of a ringstiffened Cone is shown in Figures $3 \& 4$.

\section{Results}

The theoretical elastic buckling pressures for perfect vessels, namely $\mathrm{P}_{\mathrm{cr}}$ was obtained from ANSYS and RECONEBUR; the percentage differences can be seen to be reasonable. The figures in parentheses in Table 1 are the predictions for the number of circumferential lobes (n).

Figure 3. Computer Model of a Ring-Stiffened Cone

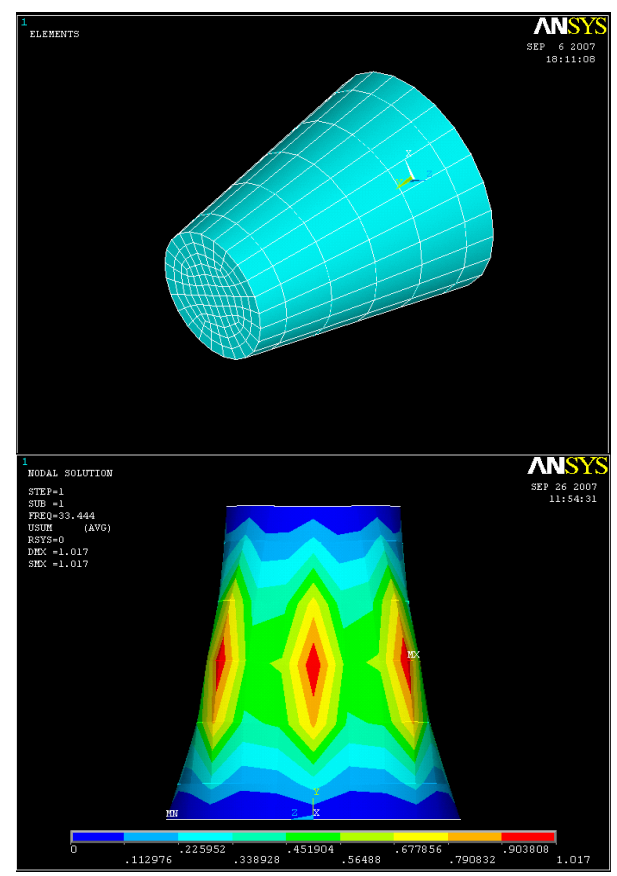

Figure 4. ANSYS Plot for the Buckled form of a ring-stiffened cone, showing the lobar pattern of deformation.

\begin{tabular}{|c|c|c|c|c|}
\hline & $\begin{array}{c}\text { ANSYS } \\
(\mathbf{M P a})\end{array}$ & $\begin{array}{c}\text { (RCONEBUR) } \\
(\mathbf{M P a})\end{array}$ & \% difference & $\begin{array}{c}\mathbf{P}_{\text {exp }} \\
(\mathbf{M P a})\end{array}$ \\
\hline Cone 13 & $27.29(4)$ & $30.90(4)$ & 11.1 & 14.07 \\
\hline Cone 14 & $31.39(4)$ & $36.26(4)$ & 15.5 & 14.55 \\
\hline Cone 15 & $37.27(4)$ & $43.51(4)$ & 16.7 & 14.48 \\
\hline
\end{tabular}

Table 1. Theoretical (Clamped edges), \& Experimental Buckling Pressures for Cones 13 to 15.

The above theoretical buckling pressures were obtained by assuming that the larger end was fixed and the smaller end was clamped. Table 1 also gives the experimental buckling pressures $\left(\mathrm{P}_{\exp }\right)$ for these vessels.

From Table 1, it can be seen that the experimental buckling pressure for Cone 15 was smaller than that of Cone 14, when it should have been larger, because the ring stiffeners for Cone 15 were larger than Cone 14, whereas all the other dimensions were the same. This is a rogue result and shows that the present method of analysis is justified as exact method of theoretical analyses are often defied.

Comparison with other theories, including ANSYS and RCONEBUR are shown in Table 2, where MisesNP is a computer program for shell instability, where the ring-stiffened cone was made equivalent to an un-stiffened circular cylinder, simply supported at its ends. The reason why RCONEBUR and ANSYS predicted higher buckling pressures than the Kendrick solutions, was 
that the Kendrick solutions assumed simply supported ends, whereas RCONEBUR and ANSYS assumed that one end of the vessel was fixed and the other end clamped. These assumptions also affect the results shown in Table 4 .

\begin{tabular}{|c|c|c|c|c|c|}
\hline CONE & KENDRICK1 & KENDRICK3 & RCONEBUR & MISESNP & ANSYS \\
\hline $\mathbf{1 3}$ & $24.03(3)$ & $23.86(3)$ & $30.90(4)$ & $20.14(4)$ & $27.29(4)$ \\
\hline $\mathbf{1 4}$ & $27.09(3)$ & $27.49(3)$ & $36.26(4)$ & $37.70(3)$ & $31.39(4)$ \\
\hline $\mathbf{1 5}$ & $33.42(3)$ & $32.56(3)$ & $43.51(4)$ & $47.45(3)$ & $37.27(4)$ \\
\hline
\end{tabular}

Table 2. Comparisons between various theories for theoretical Buckling Pressures (MPa).

\section{Design Charts.}

The thinness ratios $\left(\lambda^{\prime}\right)$ were calculated by the method described by Ross, et al, $[1,5,6]$. Circular cylindrical and conical shells, under external hydrostatic pressures, are susceptible to plastic knockdown due to the initial out-of-roundness and the thinness ratio $\left(\lambda^{\prime}\right)$; this thinness ratio was based on that used by Windenburg and Trilling [9] for un-stiffened circular cylinders. For the present case, where the vessels were ring-stiffened cones, the thinness ratio ( $\left.\lambda^{\prime}\right)$ had to be modified so that the ring-stiffened cone was approximated to an equivalent un-stiffened circular cylinder. The design charts shown in Figures 5 to 7 were obtained for the results of 12 ring-stiffened cones, tested to destruction [1,3-7], where the vertical axes were the reciprocal thinness ratios and the horizontal axes were the plastic knockdown factors. The results for Cones 13 to 15 are reported in the present text for the first time; see Tables $3 \& 4$ where: $\mathrm{P}_{\mathrm{cr}}=$ theoretical elastic buckling pressure; $\mathrm{P}_{\text {exp }}=$ experimental buckling pressure; $\lambda^{\prime}=$ thinness ratio; $\mathrm{P}_{\mathrm{cr}} / \mathrm{P}_{\mathrm{exp}}=$ plastic knockdown factor $=$ PKD.

\begin{tabular}{|c|c|c|c|c|c|c|c|}
\hline Cone & $\mathbf{P}_{\text {cr }}$ (1) & $\mathbf{P}_{\text {exp }}$ & $\begin{array}{c}\mathbf{P}_{\mathbf{c r}} \mathbf{1} / \mathbf{P}_{\text {exp }} \\
(\mathbf{P K D 1 )}\end{array}$ & $\boldsymbol{\lambda}^{\prime}$ & $\mathbf{P}_{\mathbf{c r}}$ (3) & $\mathbf{P}_{\mathbf{c r}} \mathbf{3} / \mathbf{P}_{\mathbf{e x p}}$ & $\mathbf{1} / \boldsymbol{\lambda}$ \\
$(\mathbf{P K D 3})$ & \\
\hline 13 & $24.03(3)$ & 14.07 & 1.707 & 0.821 & $23.86(3)$ & 1.696 & 1.218 \\
\hline 14 & $27.90(3)$ & 14.55 & 1.918 & 0.683 & $27.49(3)$ & 1.889 & 1.464 \\
\hline 15 & $33.42(3)$ & 14.48 & 2.308 & 0.632 & $32.56(3)$ & 2.249 & 1.582 \\
\hline
\end{tabular}

Table 3. Buckling Pressures (Kendrick-Parts $1 \&$ 3) (MPa) from present work

\begin{tabular}{|c|c|c|c|c|c|}
\hline Cone & $\mathbf{P}_{\text {cr }}$ & $\mathbf{P}_{\exp }$ & $\mathbf{P}_{\text {cr }} / \mathbf{P}_{\text {exp }}(\mathbf{P K D})$ & $\boldsymbol{\lambda}$ & $\mathbf{1} / \boldsymbol{\lambda}$ \\
\hline 13 & 30.90 & 14.07 & 2.10 & 0.821 & 1.218 \\
\hline 14 & 36.26 & 14.55 & 2.49 & 0.683 & 1.464 \\
\hline 15 & 43.51 & 14.48 & 3.00 & 0.632 & 1.582 \\
\hline
\end{tabular}

Table 4. Buckling Pressures from RCONEBUR (MPa) from the present work

From Figs. 5 to 7, it can be seen that the design charts are reasonably 'linear', where the sloping lines, which represent the effects of plastic deformation can be seen to be of linear form. To use a design chart, first $\mathrm{P}_{\mathrm{cr}}$ and $\lambda$ ' must be calculated for the appropriate vessel, then the plastic knockdown factor $\left(\mathrm{PKD}=\mathrm{P}_{\mathrm{cr}} / \mathrm{P}_{\text {exp }}\right)$ must be obtained from the appropriate design chart. Next, the predicted buckling pressure $\left(\mathrm{P}_{\text {pred }}\right)$ and the design buckling pressure $\left(\mathrm{P}_{\text {des }}\right)$ can be obtained as follows:

$\mathrm{P}_{\text {pred }}=\mathrm{P}_{\text {cr }} / \mathrm{PKD} ; \mathrm{P}_{\text {des }} \mathrm{P}_{\text {exp }} /$ safety factor. 
The 15 ring-stiffened cones were from two series. Series 1 , namely Cones 1 to 6 were longer than Series 2, namely Cones 7 to 15. Series 1 also had more ring-stiffeners than Series 2 and the halfcone angle of Series 1 was less than the half-cone angle of Series 2. Thus, the fairly linear graphs of Figs. 5 to 7 appear to show that the method of the present paper is reasonably credible because of these variations. Obviously, to give the graphs of Fig. 5-7 more credibility, it will be necessary to carry out more tests on more vessels with a larger variation in geometry and manufacturing materials.

\section{Conclusions.}

The experimental and theoretical analyses were performed on these cones successfully. The elastic theoretical analysis for perfect cones for buckling showed good agreement between the two Kendrick solutions, with less than $1 \%$ difference. The elastic theoretical analysis for perfect cones for buckling showed good agreement between the two finite element programs, namely the home produced RCONEBUR and ANSYS, with just a few percentage differences. This was found particularly encouraging as these simple theories saved design times on both RCONEBUR and especially when using ANSYS. In the case of RCONEBUR, about 20 axisymmetric shell elements were used and took several hours to analyse a vessel, and in the case of ANSYS, thousands of elements were used and it took several days to analyse the three vessel vessels. In contrast to these analyses, the 'Kendrick' approach only took a few minutes to analyse a vessel. However ANSYS had excellent post-processing facilities, which Ross' programs had not. Thus, the computer programs complemented each other and appeared also to validate each other.

Additionally, Ross [1] has made the Kendrick solutions available, free of charge, on the web; they are very easy to use.

The effects of initial out-of-circularity are very important and it must be emphasised that the vessels had very finite initial out-of-circularity. For larger values of initial out-of-circularity, the so-called safety factor will have to be made much larger; this feature has been found in the case of interframe shell instability..

The design charts should prove useful to designers, but more experimental work is required. For elastic buckling, the plastic knockdown factor, namely PKD should be equal to about one, but for plastic buckling, PKD should always be greater than one; in the design charts it can be seen that PKD approaches 5.0 for vessels that suffered considerable plastic deformation! After the elastic buckling pressure is calculated, it should be divided by PKD to give the predicted buckling pressure, this predicted buckling pressure should then be divided by a suitable safety factor.

\section{References.}

[1] Ross, C. T. F: Pressure vessels: External pressure technology, Horwood Publishing Ltd., Chichester, UK. (2001).

[2] Kendrick, S: The buckling under external pressure of circular cylindrical shells with evenly spaced equal strength, circular ring frames, -Part 1, NCRE Report No.R211, February (1953)..

[3] Kendrick, S: The buckling under external pressure of circular cylindrical shells with evenly spaced equal strength, circular ring frames, -Part 3, NCRE Report No.R244, September (1953).

[4] Ross, C T F and Hamer, H: Inelastic buckling of Ring-stiffened Circular Conical Shells under External Pressure, Proc Conf on Advances in Structural Engineering Computing, Civil-Comp Press Ltd, (1994), 109-113, 


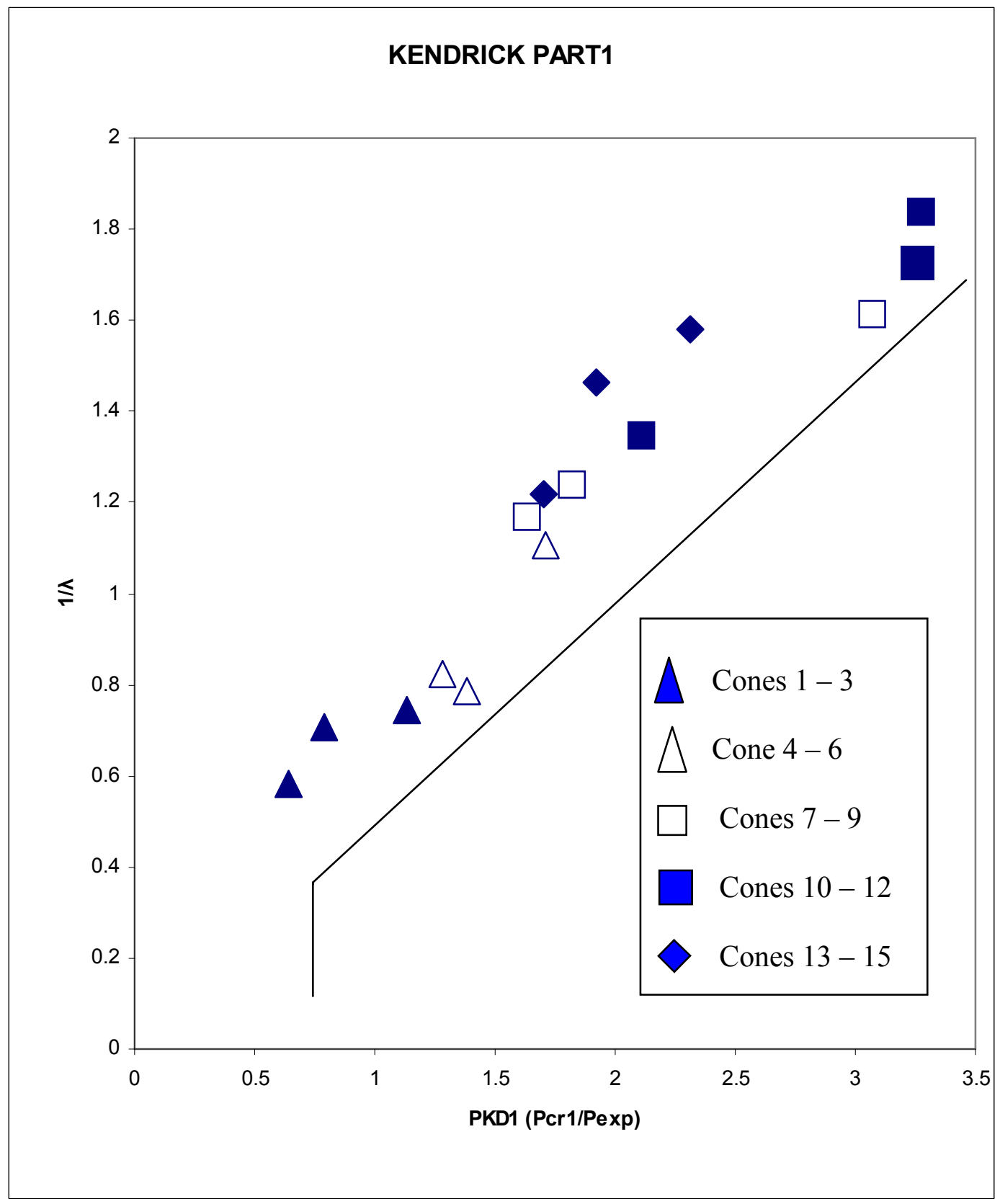

Figure 5. Design Chart using Kendrick Part 1 theory 


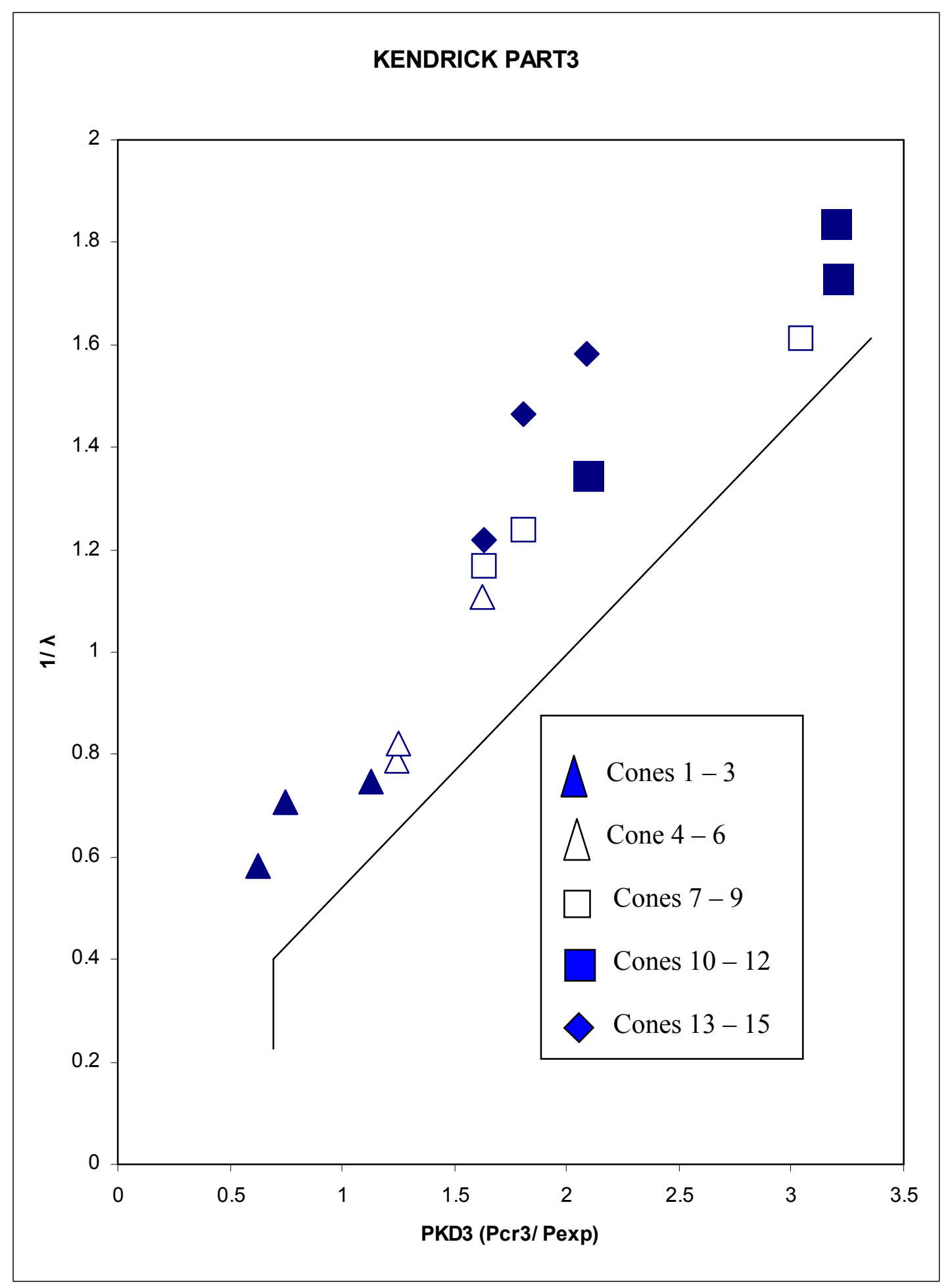

Figure 6. Design Chart using Kendrick Part 3 theory 


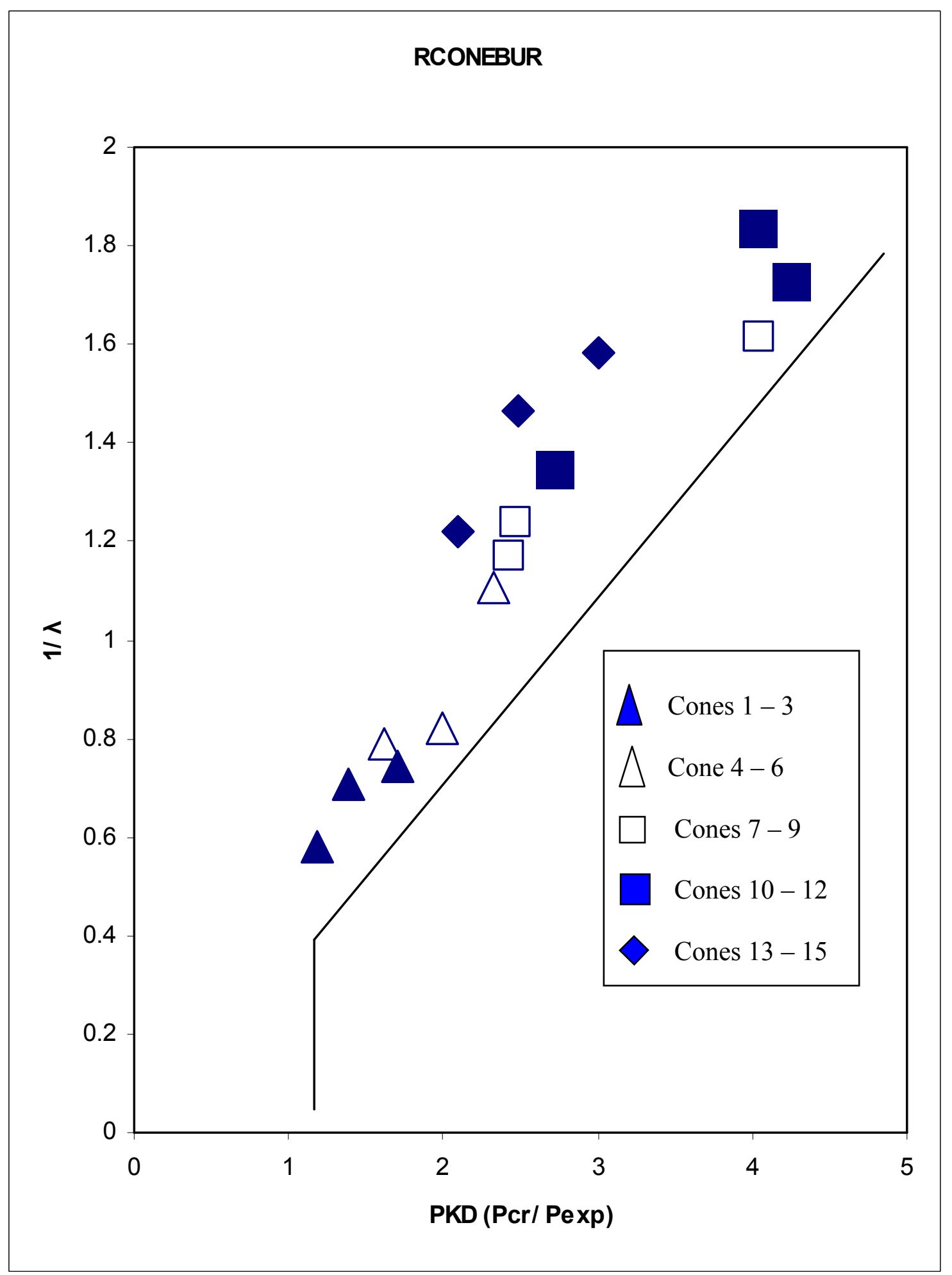

Figure 7. Design Chart for ring-stiffened conical shells, using RCONEBUR. 
[5] Ross, C. T. F., Coalter, B. and Johns, T: Design charts for the buckling of ring-stiffened circular cylinders and cones under external hydrostatic pressure, Trans R.I.N.A., Vol. 141; Part A, (1999), pp. 15-31.

[6] Ross, C.T.F., Little, A.P.F. and Adeniyi, K.A: Plastic buckling of ring-stiffened conical shell under eternal hydrostatic pressure, Ocean Engineering, 32, (2005), pp. 21-36.

[7] Ross, C.T.F., Little, A.P.F., Allsop, R., Smith, C. and Engelhardt, M: Plastic General Instability Of Ring-Reinforced Conical Shells Under Uniform External Pressure, Marine Technology,44, No. 4, (2007) pp. 268-277.

[8] Tokugawa, Takesada: Model experiments on the elastic stability of closed and cross-stiffened circular cylinders under uniform external pressure, Proc. World Eng.g Congress, Tokyo, Vol. 29, Paper No. 651, (1929), pp. 249-79.

[9] Windenburg, D. F. and Trilling, C: Collapse by instability of thin cylindrical shells under external hydrostatic pressure. Trans. ASME, Vol. 1, (1934), pp. 819-825. 